\title{
Kernos
}

Revue internationale et pluridisciplinaire de religion grecque antique

13 | 2000

Varia

\section{Attilio MASTROCINQUE, Studi sul Mitraismo (Il Mitraismo e la magia)}

Isabelle Tassignon

URL : http://journals.openedition.org/kernos/1342

DOI : 10.4000/kernos. 1342

ISSN : 2034-7871

\section{Éditeur}

Centre international d'étude de la religion grecque antique

Édition imprimée

Date de publication : 1 janvier 2000

ISSN : 0776-3824

\section{Référence électronique}

Isabelle Tassignon, «Attilio mastrocinaue, Studi sul Mitraismo (II Mitraismo e la magia) », Kernos [En ligne], 13 | 2000, mis en ligne le 21 avril 2011, consulté le 24 septembre 2020. URL : http:// journals.openedition.org/kernos/1342; DOI : https://doi.org/10.4000/kernos.1342 
est parfois sommaire et manque d'originalité et de nuance, l'exposé devient un peu elliptique. En outre, si la thèse défendue est certainement correcte, le titre est trop large. En effet, l'analyse porte sur la littérature latine - en fait, la poésie depuis le principat d'Auguste jusqu'au règne de Néron. Mais le $x^{\text {er }}$ siècle avant $\mathrm{J}$. C. ne commence pas avec l'avènement d'Auguste et le rer $^{\text {er }}$ après ne s'arrête pas à la mort de Néron. C'est d'autant plus gênant que l'époque flavienne connaîtra deux poètes mythologiques de taille, Valérius Flaccus et Stace ${ }^{1}$, qui vont remodeler à leur tour des mythes grecs : les Argonautes, la vieille saga des Sept contre Thèbes et l'histoire d'Achille.

Bruno Rochette

(Université de Liège)

Attilio Mastrocinque, Studi sul Mitraismo (Il Mitraismo e la magia), Roma, G. Bretschneider, 1998, 1 vol. $17,5 \times 25 \mathrm{~cm}, \mathrm{x}+168 \mathrm{p}$. ISBN : 88-7689-000-00.

Ces diverses études relatives au mithriacisme s'articulent autour de deux sujets : le premier est celui des rapports entretenus entre le mithriacisme et la magie; le second tend à redéfinir les notions de Mages, de magie et de mithriacisme.

Les gemmes gravées constituent la base documentaire témoignant des rapports entre mithriacisme et magie. Si les intailles sont généralement bien étudiées sur le plan de leur contenu magique, les documents associant en une même image iconographie mithriaque et alexandrine, voces magica relevant tantôt de la magie alexandrine tantôt de la liturgie mithriaque et charakteres divers furent cependant peu étudiés sous l'angle des rapports qu'elles purent entretenir avec les sectateurs de la religion mithriaque. Situation paradoxale, ces gemmes furent essentiellement mises au jour dans des régions où le mithriacisme semble être peu présent - du moins sous la forme traditionnellement connue en Europe occidentale, celle des mithrcea -, la Grèce et l'Égypte. Renonçant à l'interprétation prônée par Bonner et Festugière pour qui ces gemmes originellement mithriaques auraient été retaillées et transformées en amulettes magiques, l'A. formule deux hypothèses : la première ferait du mithriacisme une religion compatible avec la magie; selon la seconde hypothèse, ces pierres auraient été conçues par des mages qui utilisaient l'image de Mithra.

Dans les cinq premiers chapitres l'A. montre l'importance de l'iconographie mithriaque dans les gemmes magiques. Cette prédominance s'expliquerait par le pouvoir surnaturel que les mages attribuaient à certaines pierres, "pierres de foudre " comme l'obsidienne ou cristaux divers auxquels, selon Pline, les anciens prêtaient une origine astrale. L'ouvrage propose une étude détaillée de documents inédits qui se voient de la sorte judicieusement rapprochés; ainsi plusieurs chapitres sont consacrés à une analyse approfondie de la hache magique de Mentana qui présente des points communs avec une autre hache magique mithriaque trouvée dans une sépulture d'Athènes, laquelle a pu appartenir à un mage. Dépassant ensuite la stricte étude de l'iconographie et des voces magicae inscrites sur les intailles, l'A. s'interroge sur l'ancienneté des liens unissant magie et mithriacisme.

Néanmoins, les amulettes mithriaques véhiculant des expressions magiques ne constituent qu'un des maillons de la chaîne unissant mithriacisme et magie.

1 J. Henderson, Statius' Thebaid: from (p)re-made, in Fighting for Rome. Poets and Caesars, History and Civil War, Cambridge, 1998, p. 212-254 et F. RipolL, La morale béroïque dans les épopées latines d'époque flavienne : tradition et innovation, Louvainparis, 1998. 
En effet, la liturgie mithriaque paraît avoir été, elle aussi, largement empreinte de pratiques magiques; c'est ce que montrent en effet la Mithrasliturgie du grand papyrus magique de Paris ou les invocations faites à Mithra dans certaines formules magiques de guérison. Pour l'A., la «magie » procède d'une connaissance approfondie que les prêtres iraniens, - magoi -; avaient de la nature; cette connaissance se répandit peu à peu hors de la caste des « mages » pour pénétrer dans divers milieux hellénisés, imprégnés de culture grecque et, entre autres, dans les sphères où l'on vénérait Mithra. Favorable à l'interprétation jadis donnée par Cumont, selon qui le mithriacisme serait né en Asie Mineure et aurait été forgé par les magoi, l'A. précise ainsi la part que prit la culture grecque dans le développement du mithriacisme.

Alliant une connaissance approfondie de l'iconographie et des textes anciens à une parfaite maîtrise de la bibliographie, l'A., en n'hésitant jamais à éprouver des hypothèses anciennes, aboutit à une approche résolument nouvelle du mithriacisme. Cet ouvrage constitue une avancée notable dans la connaissance de la religion mithriaque et, plus largement, dans celle des courants philosophicoreligieux de l'hellénisme. Trois index (noms antiques de personnes et lieux, symboles et principaux thèmes, voces magica) complètent utilement ce travail: on regrette de n'y trouver nulle part d'index des noms d'auteurs modernes, outil dont la présence se justifierait d'autant mieux que, depuis les travaux de Cumont, le mithriacisme a nourri une abondante controverse.

Isabelle Tassignon (Université de Liège)

Elias Tempelis, The Scbool of Ammonius, son of Hermias, on Knowledge of

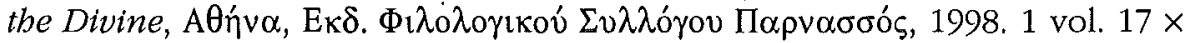
$24 \mathrm{~cm}, 168$ p. ISBN : 960-85212-5-4.

L'ouvrage est une version légèrement modifiée de la thèse de doctorat que l'auteur a soutenue en 1994, à l'Université de Londres. Il s'agit d'une étude sur la méthode et le fondement théorique de la connaissance du divin et du monde intelligible prônés par Ammonius d'Alexandrie et par ses élèves: Asclépius, Jean Philopon, Zacharie, Gessius, Pseudo-Héliodore, l'auteur anonyme du commentaire In de Interpretatione, Olympiodore et ses élèves (Élie, David, Stephanus, Pseudo-Élie, Pseudo-David et l'auteur anonyme du Prolegomena philosophicae "Syllabi » Platonicae).

Du point de vue de l'histoire des religions et de l'histoire de la philosophie, l'école d'Ammonius est intéressante à plus d'un titre. Située à Alexandrie, lieu par excellence d'échanges et de syncrétismes de toutes les traditions philosophiques et religieuses du monde méditerranéen, elle est active entre 485 et 610 de notre ère, à l'époque de la transition définitive du paganisme au christianisme. L'école reste officiellement fidèle à la religion grecque, mais les derniers élèves illustres sont des chrétiens. Sa clôture marque la fin de la longue lignée des écoles philosophiques de l'antiquité grecque. Comment les héritiers de traditions si diversifiées ont-ils affronté les grandes questions métaphysiques? L'idée longuement soutenue, fondée sur des impressions générales, que l'école d'Ammonius n'avait pas développé une doctrine métaphysique propre et qu'elle représentait surtout un effort pour couvrir la distance entre le platonisme et le christianisme a été récemment démentie par K. Verrycken (The Metaphysics of Ammonius, son of Hermeias, in R. Sorabji [ed.], Aristotle Transformed, The Ancient Commentators and their Influence, London-Ithaca-N. York, 1990). M. Tempelis vient pallier l'absence d'une recherche approfondie sur le sujet, tâche déjà déli- 